\title{
Dampak Locus of Control dan Komitmen Profesional terhadap Perilaku Etis Auditor dalam Situasi Konflik
}

\author{
Made Mega Ratnawati ${ }^{1}$ \\ Fakultas Ekonomi dan Bisnis \\ Universitas Udayana, Indonesia
}

\author{
I Ketut Budiartha ${ }^{2}$ \\ Fakultas Ekonomi dan Bisnis \\ Universitas Udayana, Indonesia
}

\begin{abstract}
Surel : megaratna.md@gmail.com
ABSTRAK

Penelitian ini bertujuan untuk mengetahui pengaruh locus of control dan komitmen profesional terhadap perilaku etis auditor dalam situasi konflik. Penelitian ini dilakukan pada kantor akuntan publik (KAP) wilayah Bali. Sampel yang digunakan dalam penelitian ini berjumlah 40 dan dalam penentuannya menggunakan teknik simple random sampling. Teknik analisis data menggunakan analisis regresi linier berganda dan pengumpulan data dilakukan menggunakan kuesioner. Berdasarkan hasil analisis ditemukan bahwa locus of control dan komitmen profesional berpengaruh positif terhadap perilaku etis auditor dalam situasi konflik. Hal ini menunjukkan bahwa auditor yang memiliki keyakinan diri atas profesinya dapat berperilaku etis pada saat pengambilan keputusan dalam situasi konflik.
\end{abstract}

Kata Kunci: Locus of Control; Komitmen Profesional; Perilaku Auditor.

The Impact of Locus of Control and Professional Commitment to The Auditor's Ethical Behavior in Conflict Situations

\section{ABSTRACT}

This study aims to determine the effect of locus of control and professional commitment on auditor's ethical behavior in conflict situations. This research was conducted at a public accounting firm (KAP) in Bali. The sample used in this study amounted to 40 and in its determination using simple random sampling technique. The data analysis technique used multiple linear regression analysis and data collection was done using a questionnaire. Based on the analysis, it was found that locus of control and professional commitment had a positive effect on auditors' ethical behavior in conflict situations. This shows that auditors who have self-confidence in their profession can behave ethically when making decisions in conflict situations.

Keywords: Locus of Control; Professional Commitment; Auditor Behavior.

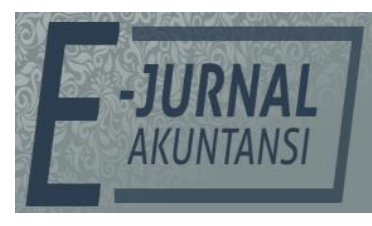

e-ISSN 2302-8556

Vol. 31 No. 4

Denpasar, April 2021

Hal. 809-821

DOI:

10.24843/EJA.2021.v31.i04.p02

PENGUTIPAN:

Ratnawati, M.M., \& Budiartha, I K. (2021).

Dampak Locus of Control dan Komitmen Profesional terhadap Perilaku Etis Auditor dalam Situasi Konflik. E-Jurnal Akuntansi, 31(4), 809-821

RIWAYAT ARTIKEL:

Artikel Masuk: 26 Oktober 2020 Artikel Diterima: 19 Februari 2021

Artikel dapat diakses : https://ojs.unud.ac.id/index.php/Akuntansi/index 


\section{PENDAHULUAN}

Setiap profesi sangat menjaga kualitas jasa yang diberikannya agar customer atau klien yang menggunakan jasa mereka percaya akan hasil kerja atau jasa yang akan dihasilkan. Salah satu profesi tersebut ialah auditor, auditor adalah pihak independen yang menjamin para pemakai laporan keuangan bahwa laporan tersebut telah disusun sesuai dengan kriteria yang telah ditetapkan (Munawir, 2008 , p. 5). Audit yang berkualitas sangat diperlukan untuk menjamin bahwa profesi akuntan publik memenuhi tanggungjawabnya kepada pihak-pihak yang mengandalkan kredibilitas laporan keuangan audit.

Profesi auditor merupakan profesi yang membutuhkan kepercayaan publik terhadap kualitas jasa yang diberikan kepada klien. Auditor harus dapat meyakinkan klien dan pemakai laporan keuangan atas kualitas audit dan jasa akuntansi lainnya. Akan tetapi, auditor selalu dihadapkan dengan dilema etika ketika akuntan berhadapan dengan pilihan antara nilai-nilai yang bertentangan yang dapat menimbulkan terjadinya konflik antara auditor dengan klien.

French \& Allbright (1998) menyebutkan konflik merupakan proses yang dimulai saat salah satu pihak merasa dikecewakan oleh pihak lain. Lubis (2010, p. 334) menyebutkan konflik dalam audit akan berkembang pada saat auditor mengungkapkan informasi yang oleh klien tidak ingin dipublikasikan kepada umum. Konflik ini akan menjadi sebuah dilema etika ketika auditor diharuskan membuat keputusan yang menyangkut independensi dan integritasnya dengan imbalan ekonomis yang mungkin dijanjikan di sisi lainnya. Dilema etika muncul sebagai konsekuensi konflik audit karena auditor berada dalam situasi pengambilan keputusan. Situasi tersebut terbentuk karena dalam konflik terdapat pihak-pihak yang berkepentingan terhadap keputusan auditor, sehingga auditor dihadapkan kepada pilihan keputusan. Morris (2014) menyebutkan bahwa seorang auditor dalam menjalankan tugasnya membuat keputusan berdasarkan kepentingan publik (sesuai undang - undang) bukan kepentingan kliennya.

Shafer (2009) dan Hidayat \& Handayani (2010) menyebutkan situasi konflik dapat terjadi ketika auditor dan klien tidak sepakat terhadap beberapa aspek fungsi dan tujuan pemeriksaan. Klien dapat mempengaruhi proses pemeriksaan yang dilakukan oleh auditor. Klien bisa menekan auditor untuk mengambil tindakan yang melanggar standar pemeriksaan, karena secara umum dianggap bahwa auditor termotivasi oleh etika profesi dan standar pemeriksaan, maka auditor akan berada dalam situasi konflik, dimana bila memenuhi keinginan klien berarti melanggar standar professional akuntan. Penolakan terhadap permintaan klien dapat menghasilkan sanksi berupa kemungkinan penghentian penugasan dan hal ini tentu saja sangat merugikan auditor. Seorang auditor yang mengalami konflik antara nilai-nilai organisasi dengan profesionalisme cenderung memiliki perilaku menyimpang selama melaksanakan tugas audit (Iswari \& Kusuma, 2013).

Soepriadi et al. (2015) menyebutkan penyimpangan perilaku dalam audit dapat disebabkan oleh faktor karakteristik personal dari auditor (faktor internal) serta faktor situasional saat melakukan audit (faktor eksternal). Pemahaman karakteristik individu dapat memungkinkan perusahaan untuk dapat meminimalisir resiko terkait penyimpangan perilaku audit (Donnelly et al., 2003). 
Salah satu aspek karakteristik kepribadian yang dimiliki oleh setiap individu adalah locus of control.

Locus of control merupakan tingkat keyakinan ketika outcome dari tindakan kita tergantung pada apa yang kita lakukan (orientasi kontrol internal) atau pada kejadian diluar kontrol pribadi kita (orientasi kontrol eksternal) (Nadirsyah \& Zuhra, 2009). Locus of control dapat dibedakan atas internal locus of control dan eksternal locus of control. Auditor yang cenderung memiliki internal locus of control berarti dia yakin akan kemampuan dirinya dalam menyelesaikan suatu permasalahan. Apabila seorang auditor mempunyai kecenderungan mempercayai faktor-faktor diluar dirinya sebagai penentu keberhasilan, maka ia memiliki eksternal locus of control (Agustia, 2011). Jones \& Kavanagh (1996) menyebutkan individu yang mempunyai locus of control internal akan lebih berperilaku etis dalam situasi dilema etis dibanding individu dengan locus of control eksternal dikarenakan individu locus of control internal mengetahui hubungan langsung antara perilaku dengan hasil yang dicapai. Chadegani et al. (2015) menyebutkan bahwa seseorang yang memiliki locus of control internal lebih menunjukkan komitmen yang tinggi kepada perusahaan daripada locus of control eksternal.

Akuntan publik memiliki prinsip etika dalam menjalankan profesinya yang diatur dalam kode etik Ikatan Akuntan Indonesia dimana dalam aturan tersebut memuat tatanan etika dan prinsip moral seorang akuntan publik dalam berhubungan dengan publik, pemakai jasa akuntan, dan rekan seprofesi. Perilaku profesional diperlukan oleh seorang akuntan publik. Jusup (2010, p. 99) menyebutkan perilaku profesional dimana setiap anggota harus berperilaku yang konsisten dengan reputasi profesi yang baik dan menjauhi tindakan yang dapat mendiskreditkan profesi. Mowday et al. (1979) menyebutkan sikap komitmen berkembang perlahan namun konsisten seiring berjalannya waktu dikarenakan individu memikirkan hubungan dengan atasannya.

Yuliani (2010) menyebutkan komitmen professional merupakan sikap untuk mempertahankan status profesi, dan memelihara citra publik terhadap ilmu dan pekerjaan profesionalnya. Alkautsar (2014) menyebutkan bahwa komitmen profesional adalah sikap kesetiaan individu pada suatu organisasi atau perusahaan dimana individu tersebut merupakan bagian dari organisasi atau perusahaan tersebut untuk mencapai kesuksesan dan tujuan organisasi atau perusahaan. Komitmen bisa menjadi acuan dalam menjalankan pekerjaan, dikarenakan bila memiliki komitmen yang kuat dapat menjaga sikap dalam mengambil tindakan (Prasetyo, 2010). Komitmen profesional merupakan determinan yang penting dalam proses pengambilan keputusan dalam dilema etis (Ford \& Richardson, 1994), dalam penelitiannya menemukan bahwa pengambilan keputusan etis merupakan determinan penting karena terdiri dari faktor-faktor yang berhubungan dengan individu pembuat keputusan.

Masalah penyimpangan dalam pengauditan yang terjadi salah satunya pada tahun 2008 dimana Kementerian Keuangan membekukan izin kantor akuntan publik (KAP) Drs. Tahrir Hidayat dan akuntan publik (AP) Drs. Dody Hapsoro. Pembekuan dilakukan karena KAP Drs. Tahrir Hidayat dan AP Drs. Dody Hapsoro telah melakukan pelanggaran terhadap standar auditing (SA) dan standar profesional akuntan publik (SPAP) dalam pelaksanaan audit atas 
laporan keuangan konsolidasi PT. Pupuk Sriwidjaya (Persero) (Mok, 2011). Selain kasus KAP Tahrir, tahun 2011 auditor BPK Manado di tangkap KPK dikarenakan menerima suap dari Walikota Tomohon. Pemberian uang suap dilakukan agar laporan keuangan Tomohon dinyatakan berstatus wajar dengan pengecualian. Mereka juga mendapatkan fasilitas berupa hotel dan sewa kendaraan dari dana pemkot Tomohon sebesar Rp 7,5 juta (Hardjanti, 2008). Kasus tersebut mencerminkan kurangnya sikap komitmen auditor dalam menjalankan profesinya.

Beberapa penelitian mengenai locus of control antara lain dilakukan oleh Utami et al. (2007), Hidayat \& Handayani (2010), Andriansyah (2010), Herawati \& Atmini (2010), dan Khoiriyah (2013) namun masih banyak ditemukan ketidak konsistenan dalam hasil penelitian. Utami et al. (2007) membuktikan bahwa locus of contol dengan kesadaran etis berpengaruh terhadap respon akuntan publik dalam situasi konflik audit. Hidayat \& Handayani (2010) dan Andriansyah (2010) juga menyatakan locus of control dan pertimbangan etis berpengaruh signifikan terhadap perilaku auditor dalam situasi konflik audit. Hasil yang berbeda diungkapkan dalam penelitian Herawati \& Atmini (2010) dan Khoiriyah (2013) yang menyatakan peneliti tidak mampu menemukan bukti bahwa interaksi antara locus of control dengan kesadaran etis mempengaruhi respon auditor dalam situasi konflik audit.

Srimindarti et al. (2015) menyebutkan locus of control merupakan tingkat keyakinan individu dimana individu tersebut dapat mengontrol faktor-faktor yang mempengaruhi dirinya. Asni et al. (2018) menyebutkan bahwa locus of control merupakan salah satu variabel yang berpotensi mempengaruhi perilaku auditor dalam situasi konflik. Utami et al. (2007) membuktikan bahwa locus of control dengan kesadaran etis berpengaruh terhadap respon akuntan publik dalam situasi konflik audit, disebutkan semakin rendah locus of control maka akan semakin rendah respon akuntan publik dalam situasi konflik audit (kecenderungan yang lebih besar untuk menolak permintaan klien). Sebaliknya, locus of control tinggi maka semakin tinggi respon akuntan publik dalam situasi konflik audit (kecenderungan yang lebih besar untuk menerima permintaan klien). Hidayat \& Handayani (2010) dan Andriansyah (2010) juga menyatakan locus of control dan pertimbangan etis berpengaruh signifikan terhadap perilaku auditor dalam situasi konflik audit. Berdasarkan penjelasan, dapat dirumuskan hipotesis sebagai berikut.

$\mathrm{H}_{1}$ : Locus of control berpengaruh positif terhadap perilaku etis auditor dalam situasi konflik.

Sulistiyo \& Ghozali (2017) menyebutkan bahwa jika auditor memiliki komitmen profesional yang tinggi, maka kemungkinan besar nilai profesi dan aturan akan dijunjung tinggi dan perilaku menyimpang kemungkinan besar akan dihindari. Maka dari itu semakin tinggi komitmen profesional auditor semakin rendah perilaku penyimpangan audit yang akan terjadi. Lord \& DeZoort (2001) menyebutkan auditor dengan keyakinan yang kuat dalam profesi akunting akan menghindari perilaku yang tidak etis dan memiliki keinginanyang kuat untuk bekerja dengan profesional sehingga kemungkinan kecil membuat kesalahan dalam membuat pernyataan audit. Sulistiyo et al. (2018) menyebutkan bahwa auditor dengan komitmen profesional yang tinggi akan 
mempertahankan nilai-nilai profesi sehingga menurunkan perilaku menyimpang auditor. Penelitian Utami et al. (2007) dan Mariati (2013) membuktikan bahwa pengaruh hubungan komitmen profesional dengan respon akuntan publik dalam situasi konflik audit adalah positif. Hal yang berbeda dikemukakan Herawati \& Atmini (2010) yang mendapatkan hasil negatif dari interaksi antara komitmen profesi dengan kesadaran etis mempengaruhi respon auditor dalam situasi konflik. Berdasarkan penjelasan, dapat dirumuskan hipotesis sebagai berikut.

$\mathrm{H}_{2}$ : Komitmen profesional berpengaruh positif terhadap perilaku etis auditor dalam situasi konflik.

\section{METODE PENELITIAN}

Design penelitian menguraikan tentang pendekatan yang cocok digunakan untuk mendapatkan jawaban masalah dan tujuan penelitian. Pendekatan yang digunakan pada penelitian ini adalah pendekatan kuantitatif yang berbentuk asosiatif. Sugiyono (2013, p. 11) menyatakan penelitian asosiatif adalah penelitian yang bertujuan untuk mengetahui hubungan antara dua variabel atau lebih.

Penelitian ini dilakukan di Kantor Akuntan Publik yang berada di wilayah Bali dan terdaftar pada Institut Akuntan Publik Indonesia. Obyek penelitian adalah suatu sifat dari obyek yang ditetapkan oleh peneliti untuk dipelajari dan kemudian memperoleh kesimpulan (Sugiyono, 2013, p. 13). Obyek penelitian ini adalah perilaku etis auditor dalam situasi konflik. Penelitian ini memiliki dua jenis variabel yaitu variabel bebas dan variabel terikat. Variabel bebas (independen variable) merupakan variabel yang mempengaruhi atau yang menjadi sebab perubahannya atau timbulnya variabel dependen/terikat (Sugiyono, 2013, p. 59). Variabel bebas dalam penelitian ini adalah locus of control dan komitmen profesional. Locus of control menurut Mariati (2013) adalah cara pandang seseorang terhadap suatu peristiwa apakah dia dapat atau tidak dapat mengendalikan (control) peristiwa yang terjadi padanya. Penelitian ini menggunakan skala The Work Locus of Control (WLCS) yang dikembangkan oleh Spector (1988). Skala pengukuran menggunakan skala likert 5 poin dengan menggunakan kuesioner yang berisi 8 item pernyataan. Komitmen profesional adalah tingkat loyalitas individu dalam pelaksanaan aturan yang memberikan pedoman bagaimana hubungan dengan klien, masyarakat, sesama rekan dan pihak-pihak lain yang berkepentingan (Putri et al., 2013). Indikator dari komitmen profesional adalah dedikasi terhadap profesi, tanggungjawab profesional, tuntutan otonomi, percaya pada pengaturan sendiri, dan perkumpulan profesi. Skala pengukuran menggunakan skala likert 5 poin dengan menggunakan kuesioner yang telah diuji oleh Ramdani (2010) yang berisi 10 item pernyataan.

Variabel terikat (dependen variabel) merupakan variabel yang dipengaruhi atau yang menjadi akibat, karena adanya variabel bebas (Sugiyono, 2013, p. 59). Variabel terikat dalam penelitian ini adalah perilaku etis auditor dalam situasi konflik. Perilaku etis auditor dalam situasi konflik dalam hal ini adalah pengambilan keputusan auditor dalam menghadapi konflik pada pelaksanaan pengauditan. Instrumen yang digunakan berupa skenario kasus pendek yang telah digunakan oleh Andriansyah (2010). Skala pengukuran berbentuk semantic defferential dengan jawaban berkisar 0 (sangat etis) sampai 100 (sangat tidak etis). 
Penentuan nilai rata-rata dilakukan dengan cara membagi jumlah nilai total jawaban responden dengan jumlah responden dalam penelitian. Penilaian variabel perilaku auditor didasarkan pada jika nilai individu lebih kecil dari ratarata (mean) maka dikategorikan etis sebaliknya jika lebih besar dari rata-rata (mean) maka dikategorikan tidak etis.

Penelitian ini menggunakan jenis data kualitatif dan kuantitatif serta sumber data sekunder dan primer. Data kualitatif adalah data yang berbentuk kata, kalimat, skema, dan gambar (Sugiyono, 2013, p. 14). Data kualitatif dalam penelitian ini berupa nama - nama kantor akuntan publik yang terdaftar dalam Direktori Kantor Akuntan Publik wilayah Bali tahun 2019. Data kuantitatif adalah data dalam bentuk angka atau data kualitatif yang diangkakan (Sugiyono, 2013, p. 13). Data kuantitatif dalam penelitian ini diperoleh dari data kualitatif yang diangkakan dengan skala likert yang mengacu pada pengukuran variabel yang digunakan. Data primer merupakan data yang didapat dari sumber pertama baik dari individu atau perorangan seperti hasil wawancara atau hasil pengisian kuesioner yang biasa dilakukan oleh peneliti (Umar, 2003, p. 69). Data primer dalam penelitian ini adalah jawaban responden melalui kuesioner. Data sekunder merupakan data primer yang telah diolah lebih lanjut dan disajikan baik oleh pihak pengumpul data primer atau oleh pihak lain misalnya dalam bentuk tabel-tabel atau diagram-diagram (Umar, 2003, p. 69). Data sekunder dalam penelitian ini adalah data yang dikumpulkan dari sumber lain yaitu daftar kantor akuntan publik (KAP) yang terdapat di Bali.

Populasi adalah wilayah generalisasi yang terdiri atas objek atau subjek yang mempunyai kualitas dan karakteristik tertentu yang ditetapkan oleh peneliti untuk dipelajari dan kemudian ditarik kesimpulannya (Sugiyono, 2013, p. 115). Populasi dalam penelitian ini adalah seluruh auditor yang bekerja pada kantor akuntan publik di Bali. Sampel adalah bagian dari jumlah dan karakteristik yang dimiliki oleh populasi tersebut (Sugiyono, 2013, p. 116). Pengambilan sampel berarti mengambil sebagian saja dari populasi untuk menggambarkan sifat populasi yang bersangkutan dan harus representative (mewakili). Metode penentuan sampel dalam penelitian ini menggunakan teknik simple random sampling yaitu pengambilan anggota sampel dari populasi dilakukan secara acak tanpa memperhatikan strata yang ada dalam populasi itu (Sugiyono, 2013, p. 118).

Regresi linear berganda digunakan untuk menganalisis apakah hipotesis penelitian terbukti signifikan atau tidak. Analisis regresi linear berganda akan dilakukan dengan menggunakan Statistical Product and Service Solution (SPSS). Adapun rumus persamaannya adalah sebagai berikut:

$$
\mathrm{Y}=\mathrm{a}+\beta_{1} \mathrm{X}_{1}+\beta_{2} \mathrm{X}_{2}+\varepsilon
$$

Dimana :

$\begin{array}{ll}\mathrm{Y} & =\text { Perilaku etis auditor dalam situasi konflik } \\ \mathrm{a} & =\text { Konstanta } \\ \mathrm{X}_{1} & =\text { Locus of control } \\ \mathrm{X}_{2} & =\text { Komitmen profesional } \\ \beta_{1} & =\text { Koefisien regresi dari locus of control } \\ \beta_{2} & =\text { Koefisien regresi dari komitmen profesional }\end{array}$




\section{HASIL DAN PEMBAHASAN}

Jumlah responden yang dijadikan sampel data penelitian mengenai pengaruh locus of control dan komitmen profesional tehadap perilaku etis auditor dalam situasi konflik (studi kasus di KAP wilayah Bali) sebanyak 40 responden, dengan masing-masing jawaban diberikan skor sebagai berikut.

\section{Tabel 1. Hasil Statistik Deskriptif}

\begin{tabular}{llllll}
\hline & $\mathrm{N}$ & Minimum & Maximum & Mean & Std. Deviation \\
\hline Locus_of_Control $\left(\mathrm{X}_{1}\right)$ & 40 & 3,0 & 4,0 & 3,400 & 0,3242 \\
Komitmen_Profesional & 40 & 3,1 & 4,8 & 3,985 & 0,3401 \\
$\left(\mathrm{X}_{2}\right)$ & 40 & 1,0 & 7,0 & 3,462 & 1,9394 \\
Perilaku_Auditor $(\mathrm{Y})$ & 40
\end{tabular}

Sumber : Data Penelitian, 2019

Tabel 1, memperlihatkan bahwa variabel locus of control memiliki nilai minimum sebesar 3,0, nilai maksimum sebesar 4,0, mean sebesar 3,400, dan std deviasi sebesar 0,3242. Hal ini menunjukkan bahwa terjadi perbedaan nilai locus of control yang diteliti terhadap nilai rata-ratanya sebesar 0,3242. Tabel 1, memperlihatkan bahwa variabel komitmen profesional memiliki nilai minimum sebesar 3,1, nilai maksimum sebesar 4,8, mean sebesar 3,985, dan std deviasi sebesar 0,3401. Hal ini menunjukkan bahwa terjadi perbedaan nilai komitmen professional yang diteliti terhadap nilai rata-ratanya sebesar 0,3401. Tabel 1, memperlihatkan bahwa variabel perilaku etis auditor memiliki nilai minimum sebesar 1,0, nilai maksimum sebesar 7,0, mean sebesar 3,462, dan std deviasi sebesar 1,9394. Hal ini menunjukkan bahwa terjadi perbedaan nilai perilaku etis auditor yang diteliti terhadap nilai rata-ratanya sebesar 1,9394.

Suatu instrumen dikatakan valid jika korelasi antara skor faktor dengan skor total bernilai positif dan nilainya lebih besar dari 0,344 ( $r>0,344)$. Hasil uji validitas menunjukkan bahwa semua korelasi antara skor faktor dengan skor total bernilai positif dan nilainya lebih besar dari $0,344(\mathrm{r}>0,344)$. Hal tersebut menunjukkan bahwa semua pernyataan tersebut mampu mengukur objek penelitian secara valid dan konsisten. Hasil uji reliabilitas menunjukkan bahwa ketiga instrumen penelitian yaitu variabel locus of control, komitmen profesional dan perilaku etis auditor dalam situasi konflik memiliki koefisien Cronbach's Alpha lebih dari 0,70. Hal ini dapat dikatakan bahwa semua instrumen reliabel sehingga dapat digunakan untuk melakukan penelitian.

Tabel 2. Hasil Uji Normalitas

\begin{tabular}{ll}
\hline Kolmogorov-Smirnov Test & Unstandardized Residual \\
\hline $\mathrm{N}$ & 40 \\
Asymp. Sig. (2-tailed) & $0,200^{\mathrm{c}, \mathrm{d}}$ \\
\hline
\end{tabular}

Sumber : Data Penelitian, 2019

Hasil pengujian statistik nonparametrik dengan menggunakan SPSS menyatakan variabel locus of control, komitmen profesional dan perilaku etis auditor dalam situasi konflik dan residual model yang dibuat berdistribusi normal. Hal ini ditunjukkan oleh Asymp.Sig yang lebih besar dari 0,05, sehingga model yang dibuat pantas digunakan untuk analisis lebih lanjut. 
Tabel 3. Hasil Uji Multikolinieritas

\begin{tabular}{lll}
\hline Variabel & Tolerance & VIF \\
\hline Locus of Control & 0,998 & 1,002 \\
Komitmen Profesional & 0,998 & 1,002 \\
\hline
\end{tabular}

Sumber: Data Penelitian, 2019

Berdasarkan hasil olahan data yang ditampilkan, ternyata koefisien tolerance lebih besar dari 0,10 dan VIF lebih kecil dari 10. Hal ini berarti bahwa tidak terdapat gejala multikolinier dari model regresi yang dibuat, sehingga model tersebut layak digunakan untuk memprediksi.

Tabel 4. Hasil Uji Heteroskedastisitas

\begin{tabular}{lll}
\hline Variabel & Sig & Keterangan \\
\hline Locus of control & 0,479 & Bebas heteroskedastisitas \\
Komitmen Profesional & 0,819 & Bebas heteroskedastisitas \\
\hline
\end{tabular}

Sumber: Data Penelitian, 2019

Berdasarkan olahan data dengan SPSS terlihat bahwa nilai sig pada masing-masing variabel berada di atas 0,05. Model yang dibuat dalam penelitian ini tidak mengandung gejala heteroskedastisitas, sehingga layak digunakan untuk memprediksi.

Tabel 5. Hasil Analisis Regresi Linear Berganda

\begin{tabular}{|c|c|c|c|c|c|c|}
\hline \multirow{2}{*}{\multicolumn{2}{|c|}{ Model }} & \multicolumn{2}{|c|}{$\begin{array}{l}\text { Unstandardized } \\
\text { Coefficients }\end{array}$} & $\begin{array}{l}\text { Standardized } \\
\text { Coefficients }\end{array}$ & \multirow[t]{2}{*}{$\mathrm{t}$} & \multirow{2}{*}{ Sig. } \\
\hline & & $\mathrm{B}$ & Std. Error & Beta & & \\
\hline & (Constant) & 1,515 & 0,283 & & 5,356 & 0,000 \\
\hline & Locus_of Con & 0,445 & 0,087 & 0,555 & 5,084 & 0,000 \\
\hline & Komitmen_Profesional & 0,240 & 0,055 & 0,479 & 4,383 & 0,000 \\
\hline
\end{tabular}

Sumber: Data Penelitian, 2019

$$
\mathrm{Y}=1.515+0.445 \mathrm{X}_{1}+0.240 \mathrm{X}_{2}+\varepsilon
$$

Nilai konstanta sebesar positif 1.515 apabila locus of control $\left(\mathrm{X}_{1}\right)$ dan komitmen profesional $\left(\mathrm{X}_{2}\right)$ maka kinerja individu mengalami peningkatan. Nilai koefisien regresi locus of control $\left(\mathrm{X}_{1}\right)$ sebesar 0.445 apabila locus of control meningkat sebesar 1 satuan dengan anggapan variabel lainnya konstan, maka perilaku etis auditor dalam situasi konflik meningkat sebesar 0.445 satuan. Nilai koefisien regresi komitmen profesional $\left(\mathrm{X}_{2}\right)$ sebesar 0.240 apabila komitmen profesional meningkat sebesar 1 satuan dengan anggapan variabel lainnya konstan, maka perilaku etis auditor dalam situasi konflik meningkat sebesar 0,240 satuan.

Adjusted $R$ Square digunakan untuk mengukur seberapa jauh kemampuan model dalam menerangkan variable dependen. Berdasarkan hasil perhitungan SPSS, didapatkan nilai Adjusted $R$ square sebesar 0,559 atau $55,9 \%$ artinya besarnya kemampuan variasi locus of control dan komitmen profesional dapat menjelaskan variabel perilaku etis auditor dalam situasi konflik sebesar 55,9\% sedangkan sisanya $44,1 \%$ dijelaskan oleh faktor lain yang tidak dijelaskan dalam analisis ini (penelitian ini). Uji statistik F pada dasarnya menunjukkan apakah semua variabel independen atau bebas yang dimasukkan dalam model mempunyai pengaruh secara bersama-sama terhadap variabel dependen/terikat. Berikut merupakan penjelasan mengenai hasil uji $\mathrm{F}$. 
Tabel 6. Hasil Uji Kelayakan Model

\begin{tabular}{lllllll}
\hline Model & & Sum of Squares & $d f$ & Mean Square & $F$ & Sig \\
\hline \multirow{2}{*}{1} & Regression & 5,356 & 2 & 1,364 & 23,491 & $0,000^{\mathrm{b}}$ \\
& Residual & 5,084 & 37 & 0,058 & & \\
& Total & 4,383 & 39 & & & \\
\hline
\end{tabular}

Sumber: Data Penelitian, 2019

Hasil perhitungan F menunjukkan angka sebesar 23,491. Angka tersebut jauh lebih besar dari $\mathrm{F}$ tabel pada derajat bebas $2: 37$ dengan level of significant 5 persen yaitu sebesar 3,25. Ini berarti bahwa secara serempak variabel locus of control dan komitmen profesional berpengaruh terhadap perilaku etis auditor dalam situasi konflik.

Uji $\mathrm{t}$ dilakukan untuk mengetahui seberapa besar pengaruh variabel independen terhadap variabel dependen secara parsial. Uji $\mathrm{t}$ ini dilakukan dengan membandingkan nilai signifikan yang dihasilkan dengan alpha 0,05. Hasil pengujian secara parsial masing-masing variabel independen terhadap variabel dependendapat dijelaskan bahwa locus of control berpengaruh positif terhadap perilaku etis auditor dalam situasi konflik. Berdasarkan hasil olahan data SPSS Tabel 5, menunjukkan hasil signifikansi kurang dari 0,05, maka $\mathrm{H}_{0}$ ditolak dan $\mathrm{H}_{1}$ diterima. Ini berarti locus of control berpengaruh positif dan signifikan terhadap perilaku etis auditor dalam situasi konflik.Komitmen profesional berpengaruh positif terhadap perilaku etis auditor dalam situasi konflik. Berdasarkan hasil olahan data SPSS Tabel 5, menunjukkan hasil signifikansi kurang dari 0,05 , maka $\mathrm{H}_{0}$ ditolak dan $\mathrm{H}_{1}$ diterima. Ini berarti komitmen professional berpengaruh positif dan signifikan terhadap perilaku etis auditor dalam situasi konflik.

Berdasarkan hasil penelitian diperoleh bahwa locus of control berpengaruh positif terhadap perilaku etis auditor dalam situasi konflik. Ini sesuai dengan hipotesis satu, bahwa locus of control berpengaruh positif terhadap perilaku etis auditor dalam situasi konflik. Hasil penelitian ini menunjukkan bahwa semakin rendah locus of control seorang auditor maka semakin rendah potensi perilaku tidak etis seorang auditor dalam menghadapi situasi konflik (kemungkinan lebih kecil untuk menerima permintaan klien) sebaliknya jika locus of control seorang auditor tinggi maka semakin tinggi potensi perilaku tidak etis seorang auditor dalam menghadapi situasi konflik (kemungkinan lebih besar untuk menerima permintaan klien). Hal ini sesuai dengan teori atribusi dimana perilaku seseorang ditentukan oleh kombinasi antara kekuatan internal (internal forces) dan kekuatan eksternal (external forces). Hasil penelitian ini sesuai dengan penelitian Utami et al. (2007), Hidayat \& Handayani (2010) serta Andriansyah (2010) yang mengemukakan bahwa locus of control berpengaruh positif terhadap perilaku etis auditor dalam situasi konflik.

Berdasarkan hasil penelitian diperoleh bahwa komitmen profesional berpengaruh positif terhadap perilaku etis auditor dalam situasi konflik. Ini sesuai dengan hipotesis satu, bahwa komitmen profesional berpengaruh positif terhadap perilaku etis auditor dalam situasi konflik. Hasil penelitian ini menunjukkan bahwa semakin tinggi komitmen profesional seorang auditor maka semakin tinggi potensi perilaku etis seorang auditor dalam menghadapi 
situasi konflik (kemungkinan lebih kecil untuk melanggar peratuan) sebaliknya jika komitmen profesional seorang auditor rendah maka semakin rendah potensi perilaku etis seorang auditor dalam menghadapi situasi konflik (kemungkinan lebih besar untuk melanggar peraturan). Individual dengan komitmen profesional yang tinggi dikarakterkan memiliki kepercayaan dan penerimaan yang tinggi dalam tujuan profesi, keinginan untuk berusaha sekuatnya atas nama profesi dan keinginan kuat untuk mempertahankan keanggotaanya dalam profesi. Hasil penelitian ini sesuai dengan penelitian Utami et al. (2007) dan Mariati (2013) yang mengemukakan bahwa komitmen profesional berpengaruh positif terhadap perilaku etis auditor dalam situasi konflik.

\section{SIMPULAN}

Berdasarkan pembahasan sebelumnya, maka dapat ditarik kesimpulan bahwa locus of control berpengaruh positif terhadap perilaku etis auditor dalam situasi konflik. Penelitian ini menyatakan bahwa hubungan locus of control yang dimiliki seorang auditor searah dengan perilaku etis auditor dalam situasi konflik. Internal atau eksternal locus of control mempengaruhi perilaku etis auditor dalam situasi konflik. Komitmen profesional berpengaruh positif terhadap perilaku etis auditor dalam situasi konflik. Hal ini berarti bahwa komitmen profesional yang dimiliki seorang auditor akan mempengaruhi perilaku etis auditor dalam situasi konflik.

Penelitian ini hanya menguji pengaruh locus of control dan komitmen profesional terhadap perilaku etis auditor dalam situasi konflik. Peneliti selanjutnya diharapkan dapat menambahkan variabel lain yang diduga berpengaruh terhadap perilaku etis auditor seperti variabel kinerja auditor, gender dan pengalaman kerja.

\section{REFERENSI}

Agustia, D. (2011). Pengaruh Locus of Control dan Perilaku Kepemimpinan Situasional Terhadap Prestasi Kerja Auditor dengan Kepuasan Kerja sebagai Variabel Intervening. Jurnal Ekuitas, 15(1), 1-22.

Alkautsar, M. (2014). Locus of Control, Commitment Profesional and Dysfunctional Audit Behaviour. International Journal of Humanities and Management Sciences (IJHMS), 2(1), 35-38.

Andriansyah. (2010). Pengaruh Locus of Control Terhadap Perilaku Auditor Dalam Situasi Konflik Audit dengan Kesadaran Etis sebagai Variabel Moderating. Skripsi. Universitas Islam Negeri Syarif Hidayatullah.

Asni, N., Dali, N., Tuti, D., \& Syafitri, A. A. (2018). The Influence of Locus of Control and Professional Commitment Toward Auditor's Behavior in Conflict Situation. IOSR Journal of Economics and Finance (IOSR-JEF), 9(4), 7583. https://doi.org/10.9790/5933-0904037583

Chadegani, A. A., Mohamed, Z. M., \& Iskandar, T. M. (2015). The Influence of Individual Characteristics on Auditor's Intention to Report Errors. Journal of Economics, Business and Management, 3(7), 710-714. https://doi.org/10.7763/joebm.2015.v3.271

Donnelly, D. P., Quirin, J. J., \& O’Bryan, D. (2003). Attitudes Toward Dysfunctional Audit Behavior: The Effects Of Locus Of Control, 
Organizational Commitment, and Position. Journal of Applied Business Research (JABR), 19(1). https://doi.org/10.19030/jabr.v19i1.2151

Ford, R. C., \& Richardson, W. D. (1994). Ethical Decision Making: A Review of the Empirical Literature. Journal of Business Ethics, 13(3), 205-221. https://doi.org/10.1007/BF02074820

French, W., \& Allbright, D. (1998). Resolving a Moral Conflict Through Discourse. Journal of Business Ethics, 17(2), 177-194. https://doi.org/10.1023/A:1005792208264

Hardjanti, R. (2008). Menkeu Bekukan Izin KAP Tahrir Hidayat \& AP Dody Hapsoro.Economy.Okezone.Com.

https:/ /economy.okezone.com/read/2008/07/19/20/129076/menkeubekukan-izin-kap-tahrir-hidayat-ap-dody-hapsoro

Herawati, T. D., \& Atmini, S. (2010). Perbedaan Perilaku Auditor dalam Situasi Konflik Dilihat dari Segi Gender : Peran Locus of Control, Komitmen Profesi, dan Kesadaran Etis. Jurnal Aplikasi Manajemen, 8(2), 531-545.

Hidayat, W., \& Handayani, S. (2010). Peran Faktor-Faktor Individual dan Pertimbangan Etis Terhadap Perilaku Auditor dalam Situasi Konflik Audit pada Lingkungan Inspektorat Sulawesi Tenggara. Jurnal Mitra Ekonomi Dan Manajemen Bisnis, 1(1), 83-112.

Iswari, T. I., \& Kusuma, I. (2013). The Effect of Organizational-Professional Conflict towards Professional Judgment by Public Accountant Using Personality Type, Gender, and Locus of Control as Moderating Variables. Review of Integrative Business and Economics Research, 2(22), 434-449. http://buscompress.com/uploads/3/4/9/8/34980536/riber_b13-172_434448_.pdf

Jones, G. E., \& Kavanagh, M. J. (1996). An Experimental Examination of the Effects of Individual and Situational Factors on Unethical Behavioral Intentions in the Workplace. Journal of Business Ethics, 15(5), 511-523. https://doi.org/10.1007/BF00381927

Jusup, A. H. (2010). Auditing (Pengauditan) Buku 1. STIE YKPN.

Khoiriyah, S. L. (2013). Analisis Faktor Personal Dan Pertimbangan Etis Terhadap Perilaku Auditor Pada Situasi Konflik Audit. Accounting Analysis Journal, 2(4), 369-377. https:// doi.org/10.15294/aaj.v2i4.2880

Lord, A. T., \& DeZoort, F. T. (2001). The Impact of Commitment and Moral Reasoning on Auditors' Responses to Social Influence Pressure. Accounting, Organizations and Society, 26(3), 215-235. https://doi.org/10.1016/S03613682(00)00022-2

Lubis, A. I. (2010). Akuntansi Keperilakuan (2nd ed.). Salemba Empat.

Mariati. (2013). Pengaruh Locus of Control dan Komitmen Profesi Terhadap Perilaku Etis Auditor pada Situasi Konflik Audit. Jurnal Riset Akuntansi Dan Bisnis, 13(1).

Mok. (2011). Diduga Terima Suap Walikota Tomohon, Dua Auditor BPK Ditahan KPK. News.Detik.Com. http://news.detik.com/berita/1718598/didugaterima-suap-walikota-tomohon-dua-auditor-bpk-ditahan-kpk

Morris, J. T. (2014). The Impact of Authentic Leadership and Ethical Firm Culture on Auditor Behavior. Journal of Behavioral Studies in Business, 7(September).

Mowday, R. T., Steers, R. M., \& Porter, L. W. (1979). The Measurement of 
Organizational Commitment. Journal of Vocational Behavior, 14(2), 224-247. https://doi.org/10.1016/0001-8791(79)90072-1

Munawir, H. . (2008). Auditing Modern Buku 1. BPFE.

Nadirsyah, \& Zuhra, I. M. (2009). Locus of Control, Time Budget Pressure dan Penyimpangan Perilaku Dalam Audit. Jurnal Telaah Dan Riset Akuntansi, 2(2), 104-116.

Prasetyo, A. P. (2010). Pengaruh Locus of Control, Pengalaman Auditor, Komitmen Profesional dan Etika Profesional Terhadap Perilaku Auditor dalam Situasi Konflik Audit. Skripsi. Universitas Islam Negeri Syarif Hidayatullah.

Putri, R. F., Maksum, A., \& Abubakar, E. (2013). Pengaruh Persepsi Profesi, Kesadaran Etis dan Independensi Auditor Terhadap Komitmen Profesi Akuntan Publik di Kota Medan. Jurnal Telaah Dan Riset Akuntansi, 6(2), 140149.

Ramdani, H. (2010). Analisis Komitmen Profesionalisme Pengaruhnya Terhadap Ketaatan Pelaksanaan Etika Profesi Akuntan Publik. Skripsi. Universitas Komputer Indonesia.

Shafer, W. E. (2009). Ethical Climate, Organizational-Professional Conflict and Organizational Commitment: A Study of Chinese Auditors. Accounting, Auditing and Accountability Journal, 22(7), 1087-1110. https://doi.org/10.1108/09513570910987385

Soepriadi, S., Gunawan, H., \& Utomo, H. (2015). Pengaruh Locus of Control, Self efficacy, dan komitmen Proffesional terhadap Perilaku Auditor Dalam Situasi Konflik Audit (Survey pada Kantor Akuntan Publik di Kota Bandung, Jawa Barat). Jurnal Akuntansi.

Spector, P. E. (1988). Development of the Work Locus of Control Scale. Journal of Occupational Psychology. https:// doi.org/10.1111/j.2044-8325.1988.tb00470.x

Srimindarti, C., Sunarto, \& Widati, L. W. (2015). The Effects of Locus of Control and Organizational Commitment to Acceptance of Dysfunctional Audit Behavior Based on the Theory of Planned Behavior. International Journal of Business, Economics and Law, 7(1), 27-35.

Sugiyono. (2013). Metode Penelitian Bisnis. Alfabeta.

Sulistiyo, H., Darsono, D., \& Subchan, S. (2018). An Empirical Study on the Role of Auditor Independence in Reducing Dysfunctional Audit Behavior of Public Accountants in Indonesia. Quality - Access to Success, 19(167), 93-97.

Sulistiyo, H., \& Ghozali, I. (2017). The Role of Religious Control in Dysfunctional Audit Behavior: An Empirical Study of Auditors of Public Accounting Firm in Indonesia. Journal of Applied Business Research, 33(5), 1047-1058. https://doi.org/10.19030/jabr.v33i5.10026

Umar, H. (2003). Riset Akuntansi. Gramedia Pustaka Utama.

Utami, I., Noegroho, Y. A. K., \& Indrawati, F. (2007). Pengaruh Locus of Control, Komitmen Profesional, Pengalaman Audit Terhadap Perilaku Akuntan Publik Dalam Konflik Audit Dengan Kesadaran Etis Sebagai Variabel Pemoderasi. Jurnal Akuntansi Dan Keuangan Indonesia, 4(2), 193-210. https://doi.org/10.21002/jaki.2007.10

Yuliani, L. R. (2010). Pengaruh Locus of Control, Komitmen Profesi dan Pengalaman Kerja Terhadap Perilaku Auditor dalam Situasi Konflik dengan 
Kesadaran Etis Sebagai Variabel Moderating. Skripsi. Universitas Negeri Yogyakarta. 